\title{
An Information System of Clinical Pathway Management Based on the Integration Between Knowledge Management and Learning Organization
}

\author{
Jiali Liu, Kai $\mathrm{Li}^{*}$ \\ Zhejiang Chinese Medical University, Hangzhou 310053, China
}

Corresponding Author Email: kaili@fudan.edu.cn

https://doi.org/10.18280/isi.240503

Received: 28 April 2019

Accepted: 20 August 2019

\section{Keywords:}

clinical pathway $(C P)$, knowledge management, learning organization, organizational performance, structural equation modelling (SEM)

\begin{abstract}
Inspired by the integration between knowledge management and learning organization (K-L integration), this paper sets up a clinical pathway (CP) management model based on K-L integration, and puts forward several hypotheses on the chain of positive impacts between $\mathrm{CP}$ management process, $\mathrm{CP}$ organizational optimization and $\mathrm{CP}$ performance. To verify the effectiveness of the model, a questionnaire survey was carried out at a provincial first-class hospital, and the survey data were subjected to reliability and validity tests. The proposed hypotheses were verified based on the reliable and valid samples. The data analysis shows that the proposed model has good fitting effect. Based on the model, the authors established an information system of CP management that enhances the CP knowledge among medical personnel, promotes medical quality and reduces the medical cost. The research results shed new light on the CP management in hospitals.
\end{abstract}

\section{INTRODUCTION}

Clinical pathway (CP) is a gradually digitized, standard medical process that treats and tests diseases $[1,2]$. The CP has been widely adopted to facilitate the communication between medical personnel and patients, train and educate medical students, standardize and optimize medical processes, as well as design and implement digitized information systems $[3,4]$. With the aid of information technology, the CP encourages patient involvement in the evaluation of medical service quality, promotes the efficiency of clinical work and enhances the quality of medical services and reduces the rate of $\mathrm{CP}$ variation $[5,6]$. Practical applications in various hospitals have proved the effectiveness of the $\mathrm{CP}$ in ensuring medical quality, controlling medical cost and optimizing medical processes. But there is a discrepancy between current and ideal clinical pathways whereby some patients are experiencing quality of care that is inefficient, disjointed, and less than ideal [7].

Traditionally, the CP is mainly implemented by medical personnel to prepare the most suitable and timely care plan for diagnosis. The dawn of the knowledge era raises new requirements on the $\mathrm{CP}$ : provide the patients with the best care by minimizing recovery delay and resource waste and maximizing the efficiency of clinical work and quality of medical services [8]. Hence, synchronous knowledge management is necessary before implementing the $\mathrm{CP}$ module in regional information network [9].

There are three dimensions in knowledge management: knowledge base, favorable environment and knowledge practice [10]. Crucial to success of organizing activities and strategies, knowledge management is a necessary measure to maintain competitive advantages in the knowledge-driven global economy $[11,12]$. In 1990, Peter M. Senge proposed the concept and construction disciplines of learning organization in The Fifth Discipline. Since then, this concept has been extensively used in organization and management. Learning organizations should be able to create, acquire and transfer knowledge and to adjust their behaviors adaptively to new knowledge in time [13]. For an organization, its competitiveness directly hinges on learning and knowledge. Facing intense competitions, medical institutions must increase the quality and efficiency of medical services through learning and knowledge management $[14,15]$.

Previous studies have shown that the CP implementation can promote organizational performance, but the promoting effect is rather weak [16]. In fact, several key intermediate factors between $\mathrm{CP}$ and organizational performance have been neglected. In an era when intangible assets have become the source of wealth and progress, knowledge management and learning organization may be the missing factors. To make up for the gap, this paper introduces the integration between knowledge management and learning organization (K-L) to the management of $\mathrm{CP}$ process, and builds a $\mathrm{CP}$ management information system based on the K-L integration, with the aim to provide the best medical care to patients.

\section{MODEL CONSTRUCTION}

\subsection{Theoretical analysis}

2.1.1 Matching between knowledge management and $\mathrm{CP}$ management

Knowledge management aims to apply professional knowledge in a systematic and organized manner. Such knowledge enables employees to work more effectively [17]. The basic activities of knowledge management include the creation, acquisition/storage, transfer and application of knowledge.

To enhance its competitiveness through knowledge management, an organization must have a clear understanding 
of the process of knowledge management and boast the relevant abilities. In general, knowledge management can be implemented in four stages: knowledge acquisition, knowledge utilization, knowledge transfer and knowledge protection [18]. In the regional information network, the CP module cannot be implemented without synchronous knowledge management. Therefore, the authors constructed a conceptual model of $\mathrm{CP}$ management according to the knowledge management process. As shown in Figure 1, the model adopts a four-stage process: $\mathrm{CP}$ assessment, $\mathrm{CP}$ preparation, $\mathrm{CP}$ execution and $\mathrm{CP}$ completion.

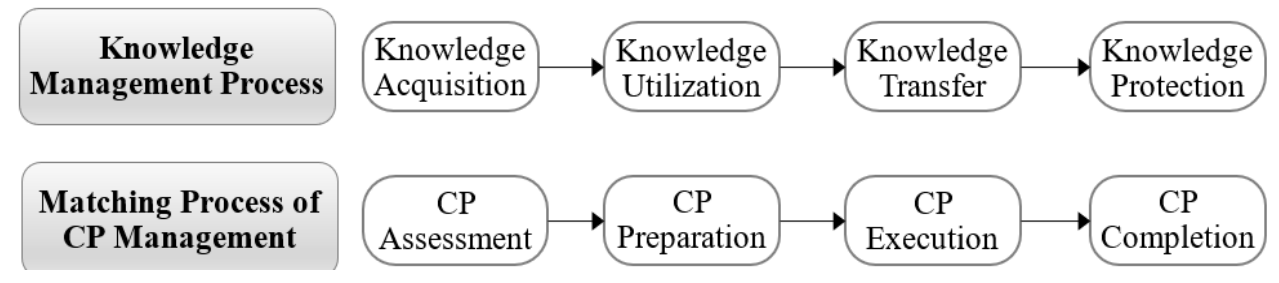

Figure 1. Matching between CP management and knowledge management

2.1.2 Matching between learning organization and $\mathrm{CP}$ management

Learning organization refers to a collection or team of people that continuously enhance their creativity [19]. There are three levels (individual learning, team learning and organizational learning) and seven dimensions of learning organization [20].

A typical learning organization should continually provide its members with learning opportunities conducive to fulfilling their goals. If so, the organization will achieve better performance, while its members will find their personal interests satisfied and will share their knowledge in an active manner [21]. To become a learning organization, ordinary organizations must shift their focus of learning from individual performance to team/organizational performance [22].

Drawing on the relevant literature, this paper defines learning organization from four aspects, namely, structural design, individual learning, team learning and systematic thinking. On this basis, a conceptual CP management model was established. As shown in Figure 2, this model covers CP structural design, $\mathrm{CP}$ individual learning, $\mathrm{CP}$ team learning and $\mathrm{CP}$ systematic thinking.

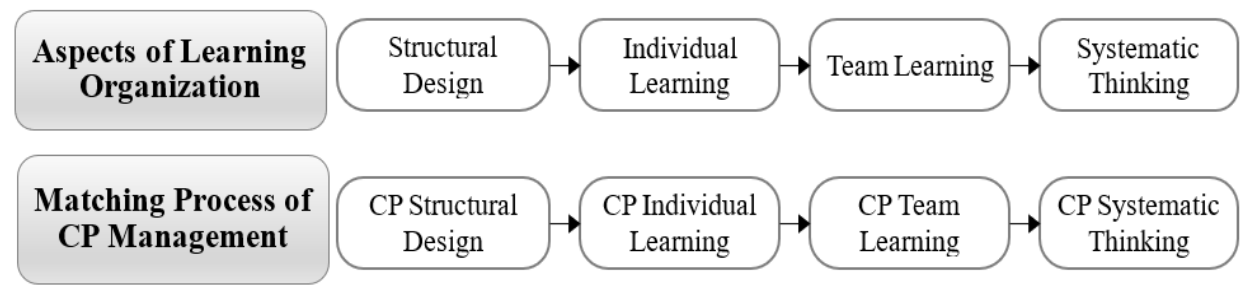

Figure 2. Matching between CP management and learning organization

2.1.3 CP management and performance evaluation based on $\mathrm{K}-\mathrm{L}$ integration

Using the balance scorecard (BSC), the knowledge assets of an organization can be measured by three indices: financial growth, internal process and customer [23]. According to the research results based on the BSC and fuzzy analysis, the knowledge management has a positive impact on supply chain performance [24]. The financial growth of an organization is affected by each aspect of learning organization. The influence mechanism is similar to chain transmission [25]. However, the non-financial indices of knowledge assets are not easy to quantify, and their impact on the financial index is mediated by the appreciation of knowledge assets.

Through the above analysis, this paper proposes a relationship model between knowledge learning and organizational performance. As shown in Figure 3, the model assumes that the K-L integration affects financial growth, which in turn influences the internal process, and then customer satisfaction and financial performance.

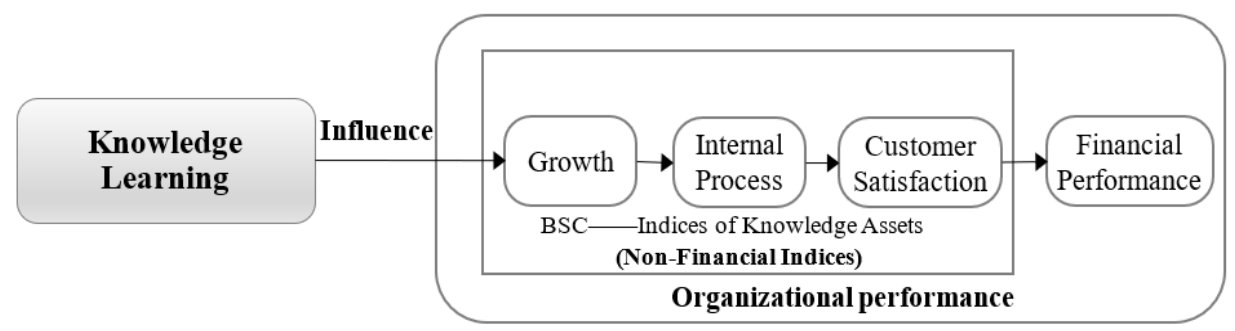

Figure 3. The relationship model between knowledge learning and organizational performance

\subsection{CP management model based on K-L integration}

Through knowledge acquisition, utilization, transfer and protection, knowledge management sums up and refines knowledge assets related to organizational business. These knowledge assets will be subjected to individual learning and team learning by the learning organization. Therefore, knowledge management provides the learning contents to the 
learning organization, while the learning organization organizes the results of knowledge management into an organic form. In our research, the learning organization depends greatly on the subjective initiative of medical personnel.
Through the analysis in Subsection 2.1, this paper puts forward a conceptual model for CP management based on K$\mathrm{L}$ integration. As shown in Figure 4, the influence of $\mathrm{CP}$ knowledge management on $\mathrm{CP}$ organizational performance is mediated by the aspects of CP learning organization.
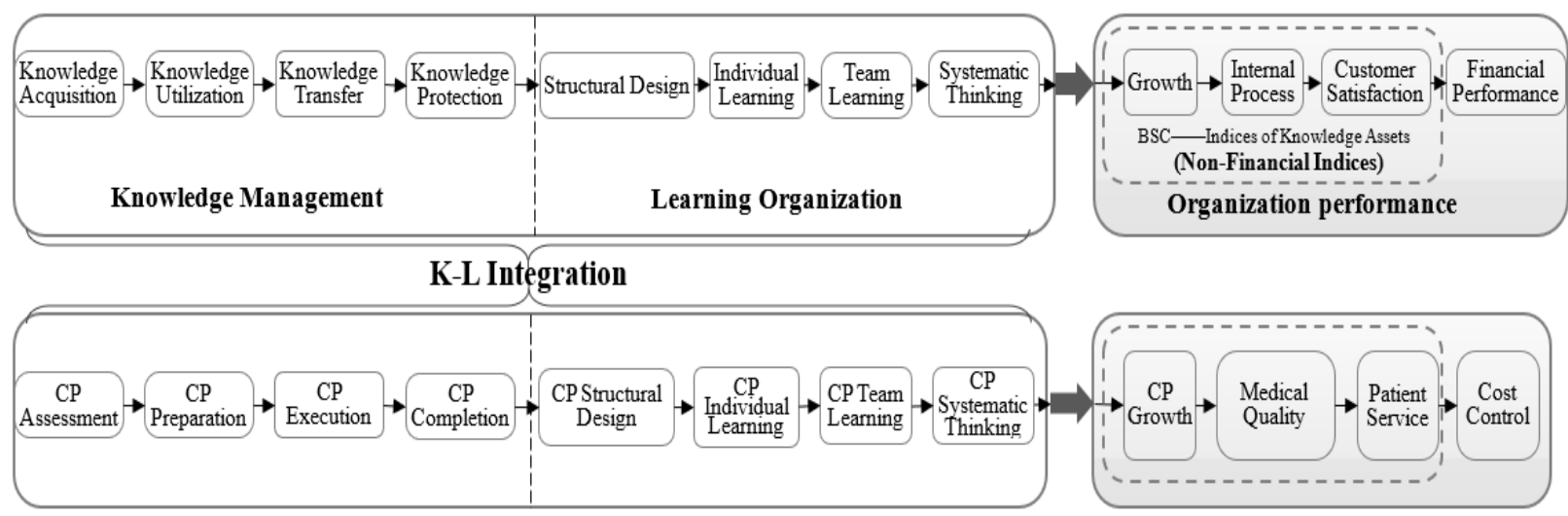

Figure 4. Conceptual model for CP management based on K-L integration

\subsection{Research dimensions}

According to the theories on knowledge management and CP management, this paper identified four research dimensions: $\mathrm{CP}$ assessment, $\mathrm{CP}$ preparation, $\mathrm{CP}$ execution and $\mathrm{CP}$ completion. Based on the theories on learning organization of CP management, another four dimensions were determined: $\mathrm{CP}$ structural design, $\mathrm{CP}$ individual learning, $\mathrm{CP}$ team learning and $\mathrm{CP}$ systematic thinking. In addition, four more dimensions were proposed for the BSC-based CP performance evaluation:
CP growth, medical quality, patient service and cost control.

\subsection{Empirical analysis method}

To verify its effectiveness, the established CP management model based on K-L integration was subjected to empirical analysis on $\mathrm{CP}$ process management, $\mathrm{CP}$ organizational optimization and CP performance. The workflow of the empirical analysis is shown in Figure 5.

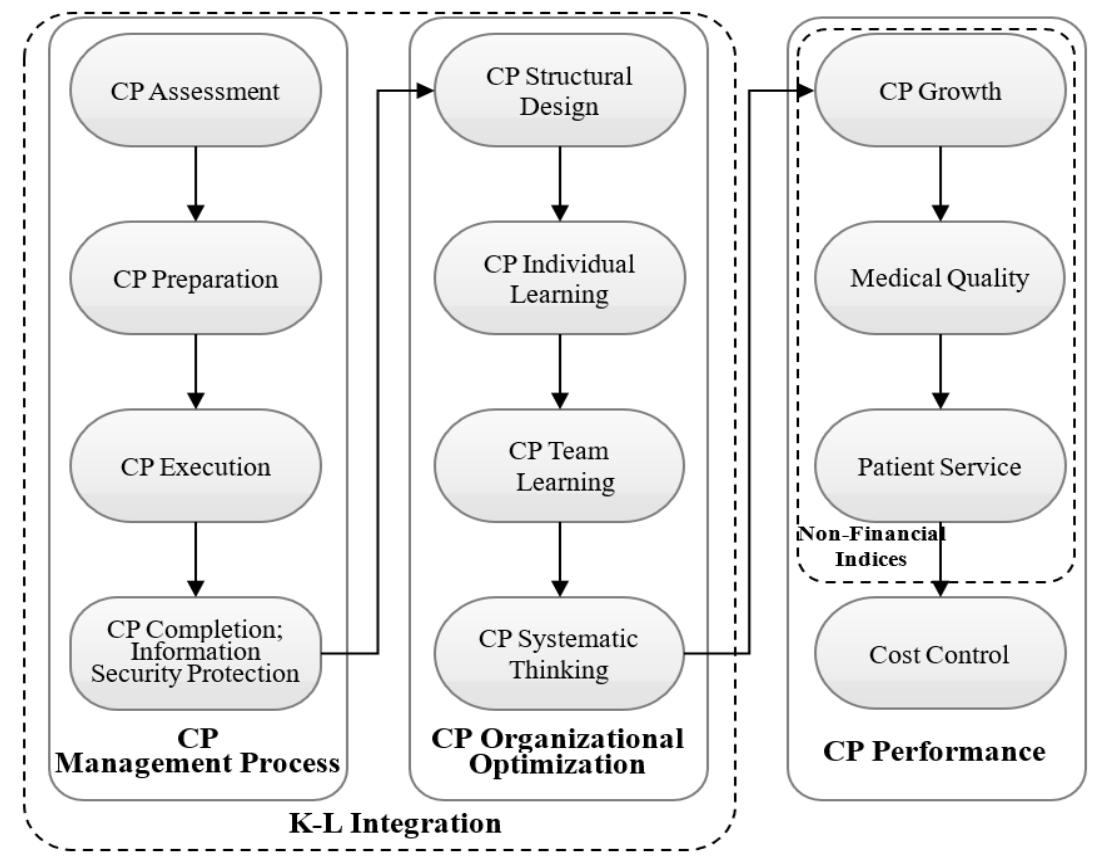

Figure 5. Workflow of empirical analysis

\subsection{Research hypotheses}

\subsubsection{Hypotheses on CP management process}

In $\mathrm{CP}$ assessment, the medical personnel need to select suitable information and knowledge assets according to the situation of the patient and the hospital. Meanwhile, CP preparation is to classify, organize and systematize the selected information and knowledge for preservation. Since $\mathrm{CP}$ assessment lays the basis for CP preparation, Hypothesis 1 was put forward.

Hypothesis 1 (H1): CP assessment has a positive impact on CP preparation.

CP execution refers to the transfer of patient situation between medical personnel, using the patient information and 
medical knowledge. Hence, the authors proposed another hypothesis.

Hypothesis $2(\mathrm{H} 2)$ : CP preparation has a positive impact on $\mathrm{CP}$ execution.

During the CP process, patient information is transmitted and exchanged among medical personnel. The privacy of the patient must be protected throughout the process. On this basis, Hypothesis 3 was developed by the authors.

Hypothesis $3(\mathrm{H} 3)$ : CP execution has a positive impact on CP completion.

\subsubsection{Hypothesis on the relationship between $\mathrm{CP}$ management} process and $\mathrm{CP}$ organizational optimization

$\mathrm{CP}$ completion marks the end of $\mathrm{CP}$ management process. The knowledge assets generated in $\mathrm{CP}$ management process will be assessed at the beginning of $\mathrm{CP}$ organizational optimization. The assessment helps the hospital to design standards on how to utilize the knowledge assets. Thus, the following hypothesis was made on the relationship between CP management process and CP organizational optimization.

Hypothesis 4 (H4): CP completion has a positive impact on $\mathrm{CP}$ organizational optimization.

\subsubsection{Hypotheses on CP organizational optimization}

Based on the objectives, management standards and evaluation criteria of the $\mathrm{CP}$, the medical personnel have the opportunity to analyze and solve problems in work, create the learning environment, and individualize training and software for each staff member. The CP structural design provides the feedback mechanism needed for effective individual learning of the CP, which arouses the learning interests of medical personnel. Therefore, Hypothesis 5 was designed on the relationship between $\mathrm{CP}$ structural design and $\mathrm{CP}$ individual learning.

Hypothesis 5 (H5): CP structural design has a positive impact on $\mathrm{CP}$ individual learning.

Through individual learning, medical personnel are familiarized with how to implement and manage $\mathrm{CP}$, and think about new CP knowledge or tackle CP problems with evidence-based medical tools. All these have a positive influence on team learning of CP. In light of this, Hypothesis 6 was presented on the relationship between CP individual learning and $\mathrm{CP}$ team learning.

Hypothesis 6 (H6): CP individual learning has a positive impact on $\mathrm{CP}$ team learning.

The team learning takes on various forms. For example, the team may visit benchmark hospitals, attend meetings and learn medical policies, with the aim to improve the internal management of CP. Thus, the team learning is beneficial to the systematic thinking of CP. On this basis, Hypothesis 7 was developed on the relationship between $\mathrm{CP}$ team learning and CP systematic thinking.

Hypothesis 7 (H7): CP team learning has a positive impact on $\mathrm{CP}$ systematic thinking.

2.5.4 Hypothesis on the relationship between $\mathrm{CP}$ organizational optimization and $\mathrm{CP}$ performance

Through CP organizational optimization, the medical personnel of the hospital can think of CP systematically. Both individuals and the medical team can realize continuous growth in their understanding of CP. As a result, Hypothesis 8 was presented on the relationship between $\mathrm{CP}$ systematic thinking and $\mathrm{CP}$ performance.

Hypothesis 8 (H8): CP systematic thinking has a positive impact on $\mathrm{CP}$ growth.

\subsubsection{Hypotheses on CP performance}

With the growing understanding of $\mathrm{CP}$, medical personnel have better abilities to use evidence-based medical tools, improve the CP system and solve the relevant problems. In this case, the quality of CP will obviously improve. This naturally leads to another hypothesis.

Hypothesis 9 (H9): CP growth has a positive impact on medical quality.

The improved medical quality, coupled with patientfriendly $\mathrm{CP}$, will boost the satisfaction of the patient. Therefore, Hypothesis 10 was suggested on the impact of medical quality on patient service.

Hypothesis 10 (H10): Medical quality has a positive impact on patient service.

The efficiency of patient service obviously suppresses the cost of hospitalization, including drug cost, inspection cost and material cost. Hence, the final hypothesis comes into being.

Hypothesis 11 (H11): Patient service has a positive impact on PC cost control.

\section{CASE STUDY}

\subsection{Methodology and data source}

\subsubsection{Methodology}

The research data were collected through a questionnaire survey based on random sampling. The survey data were subjected to reliability and validity tests. The reliable and valid data were analyzed in details to see if our hypotheses are valid.

\subsubsection{Data source}

Considering the research scope, the questionnaire survey was carried out at a provincial first-class hospital with 2,725 beds. The hospital has more than 4,100 medical personnel, working in 53 specialties, 75 wards, and 86 business departments. The respondents are clinical physicians and nurses from different departments and of varied titles.

\subsection{Survey process}

The dimensions of the CP management model based on $\mathrm{K}$ $\mathrm{L}$ integration were compiled into the questionnaire. Each question was rated by the respondents based on the Likert 5point scale. The five points correspond to strongly disagree, weakly disagree, neutral, weakly agree and strongly agree, respectively. The positive scoring method was adopted throughout the questionnaire. In other words, the higher the score, the greater the recognition of the dimension.

Both physical and online questionnaires were handed out in the said hospital. A total of 500 questionnaires were issued, and 476 were recovered, putting the recovery rate at $95.20 \%$. After discarding 8 invalid questionnaires, the authors obtained 468 valid samples.

\subsection{Data analysis}

\subsubsection{Validity tests}

The correlations between variables were measured by Kaiser-Meyer-Olkin (KMO) test of sampling adequacy and Bartlett's test for sphericity. The test results in Table 1 show that, the KMO value of all variables of our model was 0.828 , above the 0.6 threshold; the significance of Bartlett's chisquare was below 0.05 . Therefore, the null hypothesis is 
rejected, and the variables were significant the Bartlett's test for sphericity, i.e. our research samples have high overall validity.

\subsubsection{Hypotheses verification}

The structural equation modelling (SEM) is a statistical method to analyze latent variable through regression. The method fully considers the relationship between latent variables, and can process latent variables and their indices at the same time. The SEM combines factor analysis and path analysis to estimate the structure and relationship of factors, and identify the fitting degree of the entire model, making the measuring model more elastic. In this paper, the SmartPLS
(PLS: partial least squares), a robust SEM method, is adopted to verify our hypotheses. According to the SEM results in Figure 6, all the 11 hypotheses are well supported. In other words, the established model can effectively improve the $\mathrm{CP}$ performance.

Table 1. Results of validity tests

\begin{tabular}{cc}
\hline KMO & 0.828 \\
Bartlett's spherical degree & $2,763.043$ \\
Approximate chi-square & 178 \\
df & 0.000 \\
Sig. & \\
\hline
\end{tabular}
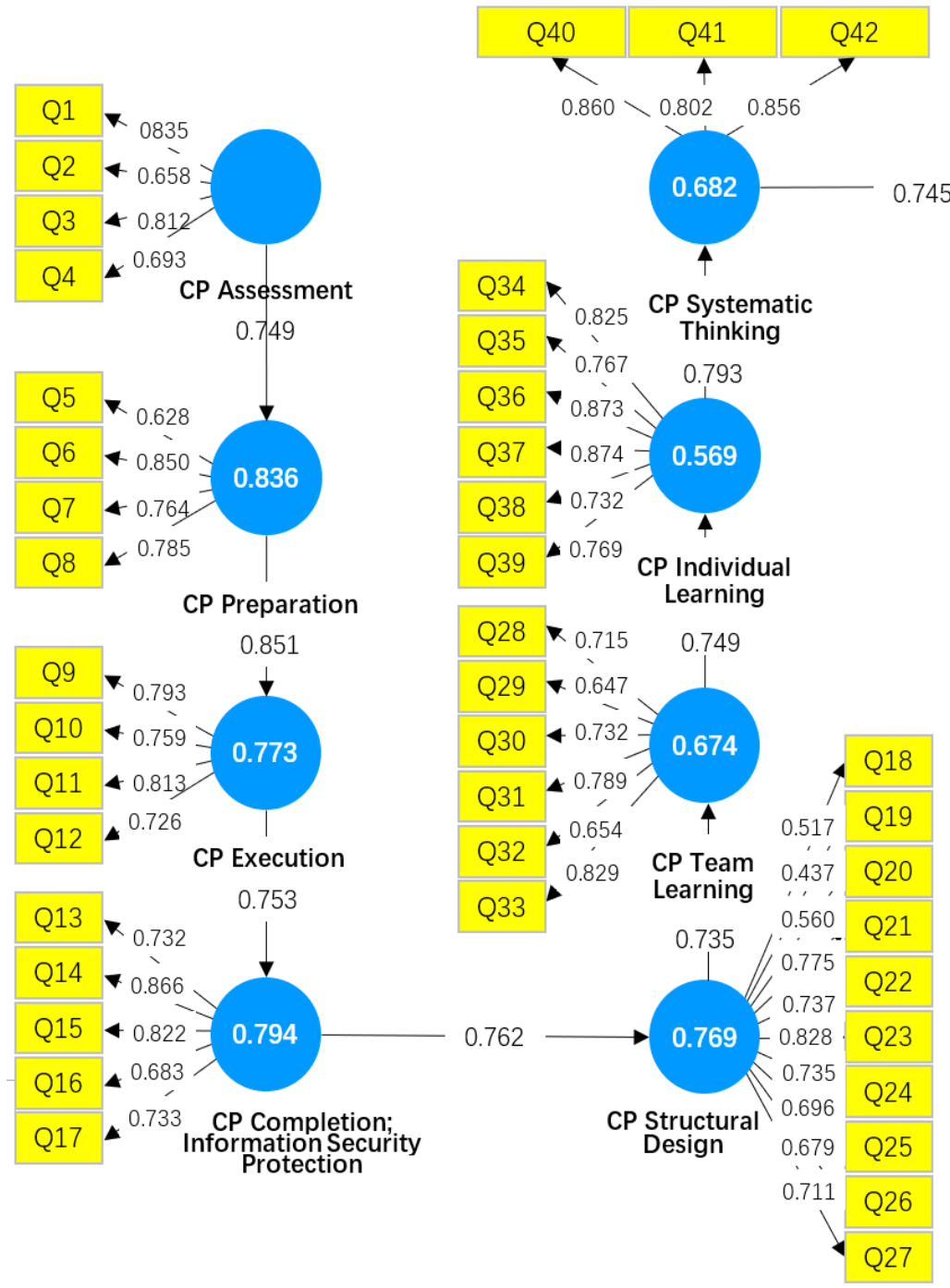

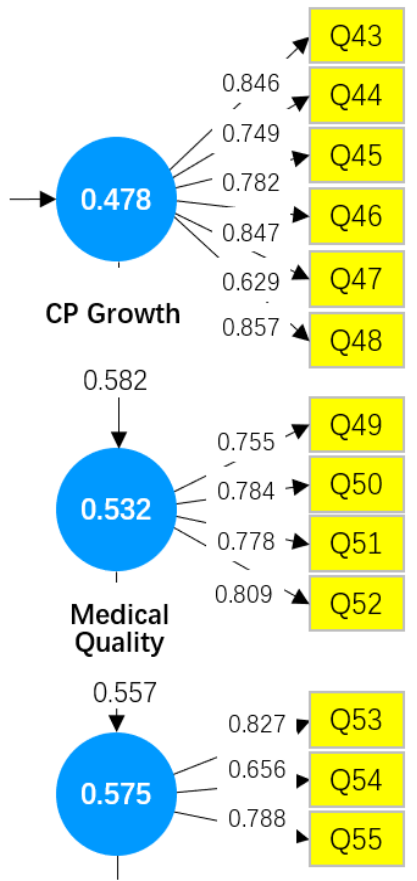

Patient Service

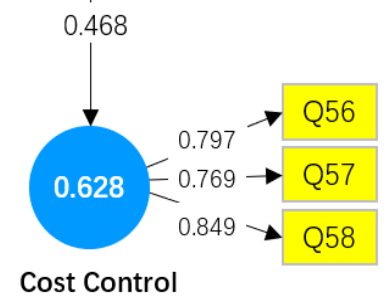

Figure 6. The SEM results

\section{DESIGN OF INFORMATION SYSTEM}

\subsection{Model construction}

The SEM analysis confirms that the $\mathrm{CP}$ management process has a positive impact on $\mathrm{CP}$ organizational optimization, which in turn has a positive impact on $\mathrm{CP}$ performance. Therefore, there is a chain of positive impact among the variables. Thus, a CP management model (as shown in Figure 7) based on K-L integration was established based on the conceptual model in Subsection 2.2.

\subsection{Implementation of information system}

Both clinical work efficiency and medical service quality can be improved by implementing informatized and digital CP. Based on the above CP management model, the authors constructed an information system that fully digitalize the CP management. The logic and framework of the information system are illustrated in Figures 8 and 9, respectively.

As shown in Figure 9, the proposed information system extracts the patient information from the hospital information system, and load the extracted information to the CP data 
storage system. The core storage components include NoSQL, HBase and Hive. Then, the $\mathrm{CP}$ analysis and evaluation are performed on machine algorithms like StreamDB. The information system improves the clinical efficiency and $\mathrm{CP}$ quality, offering patients better medical services.

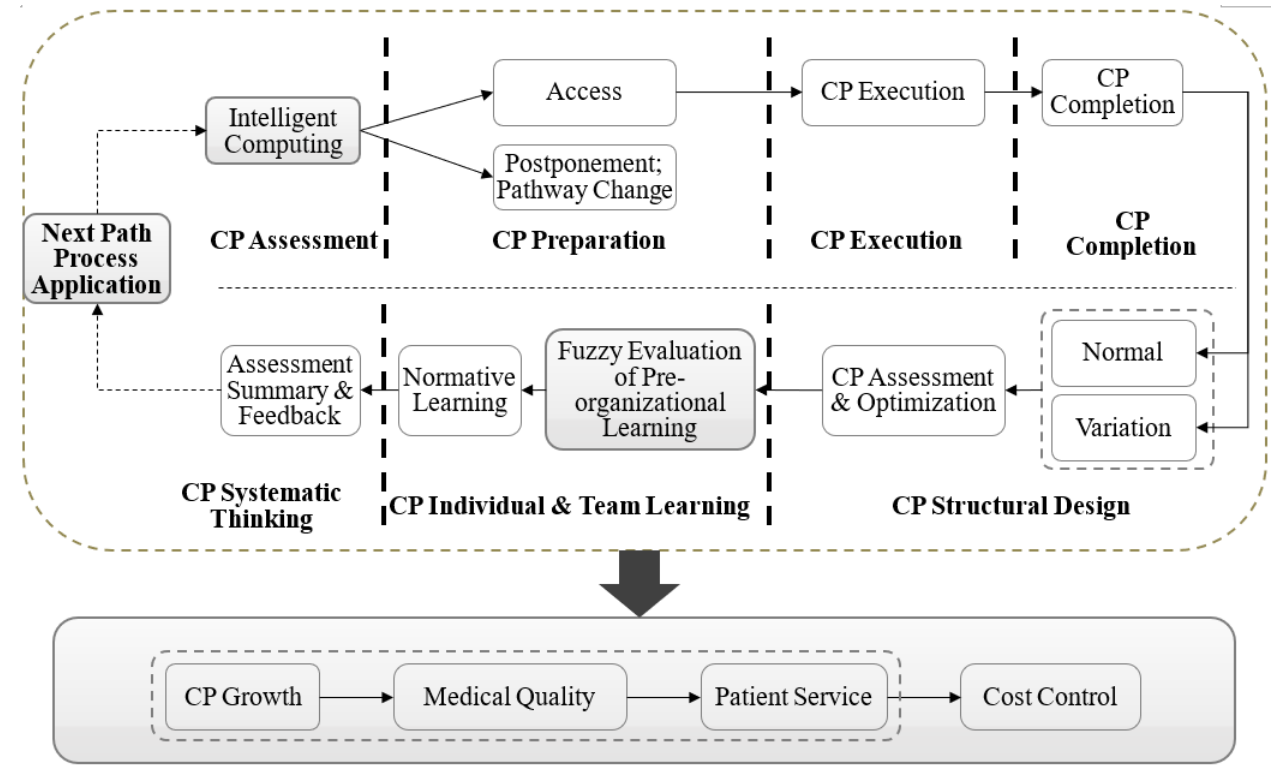

Figure 7. CP management model based on K-L integration

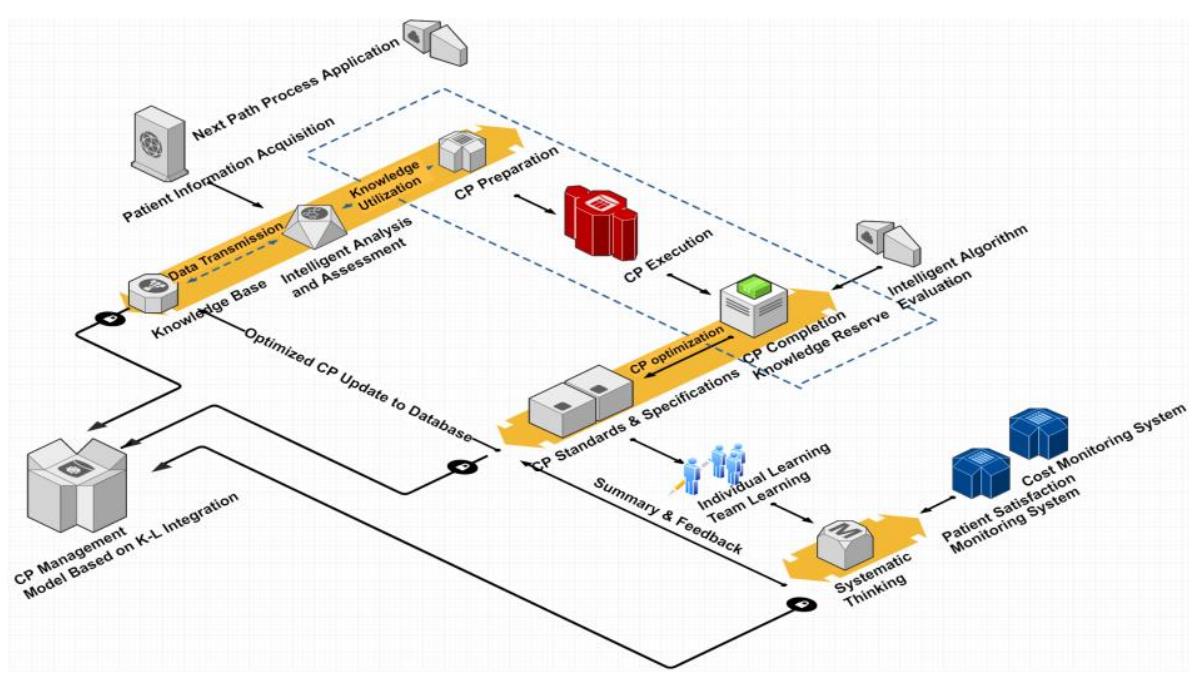

Figure 8. The logic of the information system

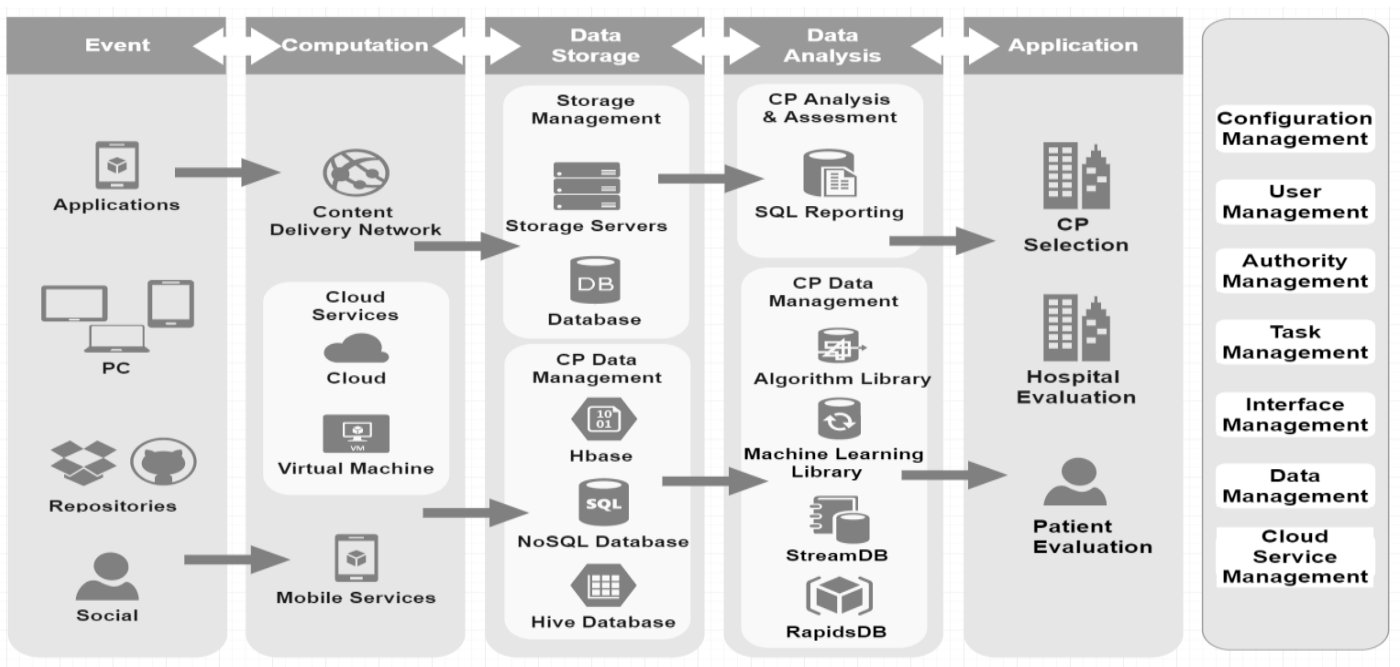

Figure 9. The framework of the information system 


\section{CONCLUSIONS}

This paper demonstrates the chain of positive impacts between $\mathrm{CP}$ process management, $\mathrm{CP}$ organizational optimization, and CP performance. Based on the theory of $\mathrm{K}$ $\mathrm{L}$ integration, the authors built a $\mathrm{CP}$ management information system that solves common CP problems among medical personnel, such as low completion rate and high mutation rate. The proposed information system helps to optimize hospital organization, improve the knowledge of medical personnel, and optimize the $\mathrm{CP}$ and the overall organizational performance. The research findings provide a good reference for hospital implementation of $\mathrm{CP}$ management, and the provision of high-quality medical services.

\section{ACKNOWLEDGEMENT}

This research was supported by Zhejiang Provincial Philosophy and Social Science foundation under Grant No. 16ZJQN049YB, Zhejiang Provincial natural science foundation under Grant No.LY16G030009 and Zhejiang Provincial Soft Science Research Program under Grant No. 2017 C25006.

\section{REFERENCES}

[1] Lawal, A.K., Rotter, T., Kinsman, L., Machotta, A., Ronellenfitsch, U., Scott, S.D., Goodridge, D., Plishka, C., Groot, G. (2016). What is a clinical pathway? Refinement of an operational definition to identify clinical pathway studies for a Cochrane systematic review. BMC Medicine, 14(1): 35-39. https://doi.org/10.1186/s12916-016-0580-Z

[2] Yamashita, T., Flanagan, B., Wakata, Y., Hamai, S., Nakashima, Y., Iwamoto, Y., Nakashima, N., Hirokawa, S. (2015). Visualization of key factor relation in clinical pathway. Procedia Computer Science, 60: 342-351. https://doi.org/10.1016/j.procs.2015.08.139

[3] Gutenstein, M., Pickering, J.W., Than, M. (2018). Development of a digital clinical pathway for emergency medicine: Lessons from usability testing and implementation failure. Health Informatics Journal, 25(4):

1563-1571. https://doi.org/10.1177/1460458218779099

[4] Shitkova, M., Taratukhin, V., Becker, J. (2015). Towards a methodology and a tool for modeling clinical pathways. Procedia Computer Science, 63: 205-212. http://doi.org/10.1016/j.procs.2015.08.335

[5] Schuld, J., Schäfer, T., Nickel, S., Jacob, P., Schilling, M.K., Richter, S. (2011). Impact of it-supported clinical pathways on medical staff satisfaction. a prospective longitudinal cohort study. International Journal of Medical Informatics, 80(3): 151-156. https://doi.org/10.1016/j.ijmedinf.2010.10.012

[6] Kasmire, K.E., Hoppa, E.C., Patel, P.P., Boch, K.N., Sacco, T., Waynik, I.Y. (2019). Reducing invasive care for low-risk febrile infants through implementation of a clinical pathway. Pediatrics, 143(3): e20181610. https://doi.org/10.1542/peds.2018-1610

[7] Eubank, B.H.F., Lafave, M.R., Preston, W.J., Sheps, D.M., Bois, A.J., Mohtadi, N.G. (2018). Evaluating quality of care for patients with rotator cuff disorders.
BMC Health Services Research, 18(1): 569-581. https://doi.org/10.1186/s12913-018-3375-4

[8] Stout, N.L., Sleight, A., Pfeiffer, D., Galantino, M.L., Desouza, B. (2019). Promoting assessment and management of function through navigation: opportunities to bridge oncology and rehabilitation systems of care. Supportive Care in Cancer. 27(12): 4497-4505. https://doi.org/10.1007/s00520-019-047410

[9] Jimenez-Molina, A., Gaete-Villegas, J., Fuentes, J. (2018). ProFUSO: Business process and ontology-based framework to develop ubiquitous computing support systems for chronic patients' management. Journal of Biomedical Informatics, 82: 106-127. https://doi.org/10.1016/j.jbi.2018.04.001

[10] Reich, B.H., Gemino, A., Sauer, C. (2012). Knowledge management and project-based knowledge in it projects: a model and preliminary empirical results. International Journal of Project Management, 30(6): 663-674. https://doi.org/10.1016/j.ijproman.2011.12.003

[11] Castrogiovanni, G., Ribeiro-Soriano, D., Mas-Tur, A., Roig-Tierno, N. (2016). Where to acquire knowledge: adapting knowledge management to financial institutions. Journal of Business Research, 69(5): 1812-1816. https://doi.org/10.1016/j.jbusres.2015.10.061

[12] Santoro, G., Vrontis, D., Thrassou, A., Dezi, L. (2018). The internet of things: building a knowledge management system for open innovation and knowledge management capacity. Technological Forecasting and Social Change, 136: 347-354. https://doi.org/10.1016/j.techfore.2017.02.034

[13] Mattison, H. (2000). The fifth discipline: The art and practice of the learning organization. New York: Bantam Doubleday Deli, 17(1): 99-99. https://doi.org/10.1109/ms.2000.820021

[14] Champagne, F., Lemieux-Charles, L., Duranceau, M. F., Mackean, G., Reay, T. (2014). Organizational impact of evidence-informed decision making training initiatives: A case study comparison of two approaches. Implementation Science, 9(1): 53-77. https://doi.org/10.1186/1748-5908-9-53

[15] Copley, L.A., Sharps, C.H., Gerardi, J.A., Gupta, S.K., Vanderhaave, K.L., Lovejoy, J.F., Albanese, S.A., Jo, C. (2019). Electronic medical record use and satisfaction among pediatric orthopaedic surgeons. Journal of Pediatric Orthopaedics, 39(9): e722-e728. https://doi.org/10.1097/BPO.0000000000001044

[16] Geerligs, L., Shepherd, H., Rankin, N., Masya, L., Cuddy, J., White, F., Shaw, J., Butow, P. (2019). Factors influencing organisational readiness for implementation of the Australian clinical pathway for the screening, assessment and management of anxiety and depression in adult cancer patients. Asia-Pacific Journal of Clinical Oncology, 15(S9), 139-139.

[17] Sanz, S., Haupt, K., Maas, A., Jober, R., Prescott, B. (2019). Optimization of knowledge transfer in ITER. Fusion Engineering and Design, 146(A): 1385-1389. https://doi.org/10.1016/j.fusengdes.2019.02.088

[18] Cerchione, R., Esposito, E. (2016). A systematic review of supply chain knowledge management research: State of the art and research opportunities. International Journal of Production Economics, 182: 276-292. https://doi.org/10.1016/j.ijpe.2016.09.006

[19] Argote, L., Hora, M. (2017). Organizational learning and 
management of technology. Production and Operations Management, 26(4): 579-590. https://doi.org/10.1111/poms.12667

[20] Larson, D.B., Donnelly, L.F., Podberesky, D.J., Merrow, A.C., Sharpe, R.E., Kruskal, J.B. (2017). Peer feedback, learning, and improvement: Answering the call of the institute of medicine report on diagnostic error. Radiology. 283: 231-241. https://doi.org/10.1148/radiol.2016161254

[21] Kim, M.Y., Oh, S. (2016). Assimilating to hierarchical culture: A grounded theory study on communication among clinical nurses. PLoS ONE, 11(6): e015630. https://doi.org/10.1371/journal.pone.0156305

[22] Ojha, D., Struckell, E., Acharya, C., Patel, P.C. (2018). Supply chain organizational learning, exploration, exploitation, and firm performance: A creationdispersion perspective. International Journal of Production Economics. 204: 70-82. https://doi.org/10.1016/j.ijpe.2018.07.025

[23] Leksono, E.B., Suparno, S., Vanany, I. (2019). Integration of a balanced scorecard, DEMATEL, and ANP for measuring the performance of a sustainable healthcare supply chain. Sustainability. 11(13): 36263643. https://doi.org/10.3390/su11133626

[24] Patil, S.K., Kant, R. (2016). Evaluating the impact of knowledge management adoption on supply chain performance by BSC-FANP approach: an empirical case study. TÉKHNE - Review of Applied Management Studies, 14(1):

52-74. https://doi.org/10.1016/j.tekhne.2016.07.004

[25] Qi, C., Chau, P.Y.K. (2018). Will enterprise social networking systems promote knowledge management and organizational learning? An empirical study. Journal of Organizational Computing and Electronic Commerce, 28(1): 31-57. 